\title{
Fast-Converging Speed and Zero Oscillation MPPT Method for PV system
}

\author{
Dr.G.Sree Lakshmi ${ }^{1}$ and Dr. S. Harivardhagini ${ }^{2}$ \\ ${ }^{1}$ Professor, CVR College of Engineering/EEE Department, Hyderabad, India \\ Email: sreelakshmisampath@gmail.com \\ ${ }^{2}$ Professor, CVR College of Engineering/EIE Department, Hyderabad, India \\ Email: harivardhagini@gmail.com
}

\begin{abstract}
This paper proposes Photovoltaic (PV) system with Maximum Power Point Tracking (MPPT). The DC-DC boost converter is used for DC loads. The PV panels are simulated in a circuit-based model and are proposed to evaluate and analyze the electrical behavior of a PV panel concerning the change in environmental conditions like irradiance and temperature. Different types of algorithms and switches are used in MPPT techniques depending on the operating conditions of the array. Perturb and Observe (P\&O) is the basic MPPT method, Incremental Conductance Method is another MPPT method and Conventional Beta MPPT method is the one used in this paper. The Conventional Beta Method ensures higher efficiency in terms of tracking time, power loss, voltage and it can also further reduce the oscillations around the MPP of a PV panel under steady-state conditions. The improved Beta MPPT method achieves all the objectives of MPPT in eliminating the oscillations around the PV power systems. A DC-DC boost converter is used to get constant $\mathrm{DC}$ voltage output by changing $\mathrm{DC}$ panel voltage and hence duty cycle of the converter is calculated accordingly. The proposed method is simulated using MATLAB/SIMULINK and the results are presented.
\end{abstract}

Index Terms: DC-DC Boost Converter, Perturb and Observe Algorithm (P\&O), Incremental Conductance Algorithm (INC), Conventional Beta Method, Maximum Power Point Tracking (MPPT), Photovoltaic (PV) system, Solar PV module, Zero oscillation, and fast converging speed.

\section{INTRODUCTION}

Photovoltaic (PV) [1] frameworks have been used for a long time. Today, with the emphasis and prominence on greener wellsprings of intensity, PV has turned into a critical intensity for a wide-ranging variety of utilizations. Enhancement in changing over light vitality into electrical vitality and the cost decreases has made this development. Indeed, even with higher productivity and lower cost, the objective stays to amplify the power from the PV framework under different lighting conditions. Photovoltaic (PV) energy is gaining popularity and regarded as one of the most important sustainable energy sources in the recent times [2]. The photovoltaic energy is a spotless vitality, with a long life expectancy and a high firm quality. In this way, it can be considered as a standout amongst the most practical of sustainable power sources. Solar cells are the essential parts of photovoltaic panels. Most of them are produced by using silicon even though various materials are additionally utilized. Solar-powered cells exploit the photoelectric impact: the capacity of a few semiconductors to change over electromagnetic radiation straightforwardly into electrical current. In other words, the Photovoltaic (PV) effect is the conversion of sunlight energy into electricity. The basic component of a photovoltaic system is the photovoltaic cell. These cells are designed to form a photovoltaic panel and are grouped to form a photovoltaic array [3]-[5].

The solar-powered cell V-I characteristics are nonlinear and alter with light and temperature. The output power of the PV system changes with changes in irradiation and temperature. Therefore, a maximum power tracking algorithm is needed to extract maximum output power from the PV system. There is a novel point on the V-I or V-P bend, called the Maximum Power Point (MPP), at which the whole PV framework works with most extreme ability [6]-[7]. The area of the MPP is not known, however, it can be found, either through figuring models or by seeking calculations. Accordingly, Maximum Power Point Tracking (MPPT) strategies are expected to keep up the PV working point at its MPP. Many maximum power point tracking techniques have been proposed, such as Perturb and Observe method, Incremental Conductance Method, Conventional Beta method, and proposed method. These methods vary in their simplicity, convergence speed, and hardware implementation. Depending upon the performance in steady and transient stages, the proposed method gives higher performance when compared to other methods [8]-[10].In this paper, a PV array is modeled in MATLAB/ SIMULINK environment and peak power is tracked using the proposed MPPT technique. The proposed method is simulated in a circuit-based approach in addition to this a DC-DC boost converter is also simulated and the duty cycle of the converter is derived according to the maximum power point determined by the MPP tracker. The goal is to achieve a constant DC output voltage from the converter to feed the DC load.

\section{SYSTEM CONFIGURATION}

A sun-powered cell essentially is a p-n semiconductor intersection. At the point when presented to light, a DC is produced. The produced current differs straight with the sunpowered irradiance. The amount of radiation falling on a Solar 
based cell alters over daylight directly to DC control. Thus, the Photovoltaic cell present in the PV panel creates power from the sun. PV board work under the phenomenon of photoelectric impact. Figure 1shows the cross-section of a PV cell. At a point where the sun-based cell is accessible to daylight, it changes over sun-powered vitality into electrical vitality. The framework arrangement for this theme is as indicated in Figure 2.Here the PV exhibit is a mix of arrangement and parallels sun powered cells. This exhibit builds up the power from the sun-oriented vitality straightforwardly and it will be switched by depending upon the temperature and sun-based irradiances.

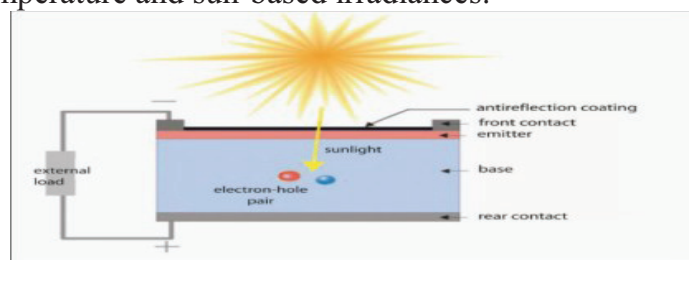

Figure 1. Cross-Section of a PV Cell

\section{A. Components of a Solar PV Panel}

A typical solar PV system consists of a solar panel, charge controller, batteries, inverter, and the load. Figure 2. shows the block diagram of such a system.

\section{B. Charge Controller}

At a point where the battery is combined into a framework, then there will be a need for a charge controller. A charge controller is used to control the unverifiable voltage developed in the system. On a fine bright day, the sunlight-based cells create more voltage which results in reducing the battery harm, and the power created doesn't run back to the solar panels overnight resulting in draining the batteries. Some charge controllers are available with additional capabilities, like lighting and load control, but managing the power is its primary job. A solar charge controller is available in two different technologies, PWM and MPPT. The performance in a system is very different from each other.

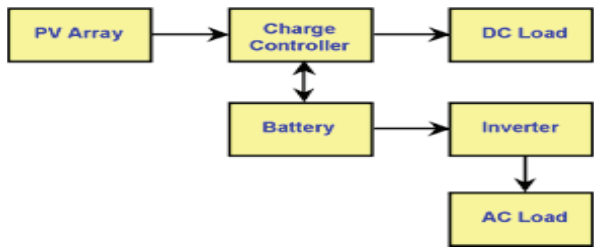

Figure 2. Components Grid

An MPPT charge controller is more expensive than a PWM charge controller, and it is often worth it to pay the extra money. A charge controller keeps up the adjust in charging the battery.

\section{Batteries}

Batteries are used to store the charges. The stored chemical energy is directly converted into electrical energy by a battery that consists of one or more electrochemical cells. The electrons flow from the negative to the positive terminal, which injects an electrical current when an external load is connected. To store the charges, batteries are utilized. Batteries are used to store energy when excessive generation is taking place and give back to gird during peak loads. They are playing a very important role in Smart Grid, as they can charge during periods of low demand and feed their stored energy into the grid when demand is high. There are abundant types of batteries available in the market. For the most part, utilized batteries are nickel/cadmium batteries.

\section{Inverter}

An inverter is an electrical device that converts direct current (DC) to alternating current (AC); the converted $\mathrm{AC}$ can be at any required voltage and frequency with the use of appropriate transformers, switching, and control circuits. Solid-state inverters have no moving parts and are used in a wide range of applications, from small switching power supplies in computers, to large electric utility high-voltage direct current applications that transport bulk power. Inverters are commonly used to supply AC power from DC sources such as solar panels or batteries. Sun oriented board produce $\mathrm{dc}$ power, yet the greater part of the family unit and mechanical apparatuses require air conditioning current.

\section{E. Characteristics of a Solar Module}

When the sunlight is incident on the cell of the solar panel, some of the photons present in that area are absorbed by the solar cells. Some of the absorbed photons will have energy greater than the energy gap between the valence band and conduction band in the semiconductor crystal. Hence, one valence electron gets energy from one photon and becomes excited and jumps out from the bond and creates one electronhole pair. These electrons and holes of e-h pairs are called light-generated electrons and holes. The light-generated electrons near the $\mathrm{p}-\mathrm{n}$ junction are migrated to the n-type side of the junction due to the electrostatic force of the field across the junction. Similarly, the light-generated holes created near the junction are migrated to the p-type side of the junction due to the same electrostatic force. In this way, a potential difference is established between two sides of the cell and if these two sides are connected by an external circuit current will start flowing from positive to the negative terminal of the solar cell. This was a basic working principle of a solar cell. While choosing a solar cell for a specific project, it is essential to know the rating of a solar panel. These parameters tell us how efficiently a solar cell can convert the light to electricity.

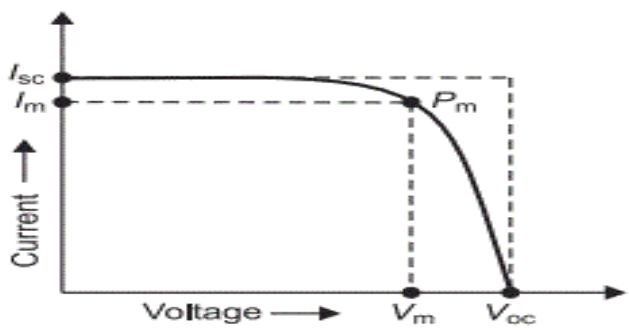

Figure 3. V-I Characteristics of Solar Cell 
F. Solar Module Parameters

Module type:user defined

Maximum power:60W

Voltage at maximum power: $17.1 \mathrm{~V}$

Current at maximum power: $3.5 \mathrm{~A}$

Open-circuit voltage: $21.1 \mathrm{~V}$

Short-circuit current:3.8A

Temperature coefficient of $\mathrm{V}_{\mathrm{oc}}:-0.1 \mathrm{mV} /{ }^{\circ} \mathrm{C}$

Temperature coefficient of $\mathrm{I}_{\mathrm{sc}}: 0.065 \% / \circ \mathrm{C}$

\section{Role OF MpPt IN Solar Power System}

Photovoltaicpower generation is one of the major keys to resolve energy demand. Photovoltaic systems often use the MPPT technique to uninterruptedly pass on the most lifted possible capacity to the load whenever there is a change in the variation of division and temperature. The Power generated through the PV system has its advantages like pollution-free and cheap.

PV modules still have large low-change efficiency; in this way, controlling the most extraordinary power point following (MPPT) for the sun arranged show is essential in a PV structure. The Maximum Power Point Tracking (MPPT) is a methodology used as a part of electronic circuits used to isolate the most extraordinary essentialness from the Photovoltaic (PV) Systems. Nowadays, the PV control age has expanded more widely due to its different purposes of enthusiasm, to enhance the vitality productivity; it is authoritative to work the PV framework consistently at its most extreme power point. Abundant maximum extreme power point Tracking (MPPT) strategies are available and proposed different techniques for obtaining the greatest power point. In any case, among the accessible method's adequate similar examination especially with variable ecological conditions is not finished. A sun-powered cell essentially is a p-n semiconductor intersection. At the point when presented to light, a direct current is produced. The produced current differs straight with the sun-powered irradiance.

\section{A. $\quad$ PV Equivalent Circuit}

Solar cells are connected in series and parallel to set up the solar array. Solar cells will produce dc voltage when it is exposed to sunlight.Solar cells can be regarded as a non-linear current source.Its generated current depends on the characteristic of material, age of solar cell, irradiation and cell temperature.

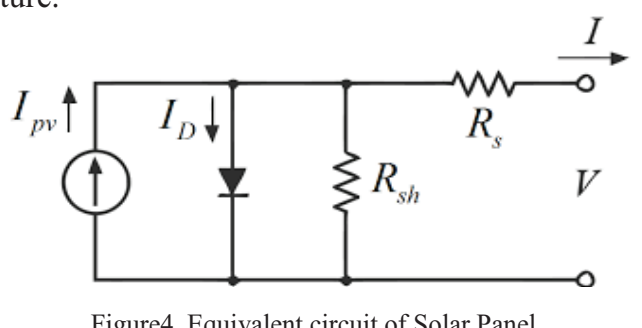

The fundamental equation that describes the I-V characteristics of the PV model is given by the equation

$$
I=I_{L}-I_{0}\left(e^{\frac{q\left(V-I R_{S}\right)}{A k T}}-1\right)-\frac{V+I R_{S}}{R_{s h}}
$$

This equation shows the dependence of PV current on temperature and hence the dependence of power drawn from the PV array.

\section{B.PV System with MPPT control}

The MPPT method is extensively used in order to maximize power control extraction irrespective of the environmental conditions. PV bodies exist in various configurations with respect to their relationship to inverter frameworks, outer lattices, battery banks, or other electrical burdens. Nevertheless, a definitive goal of the sun powered power; however, the crucial issue tended to MPPT is that the productivity of intensity exchange from the sun-based cell depends upon both the measure of daylight falling on the sunoriented boards and the electrical characteristics of the mound.

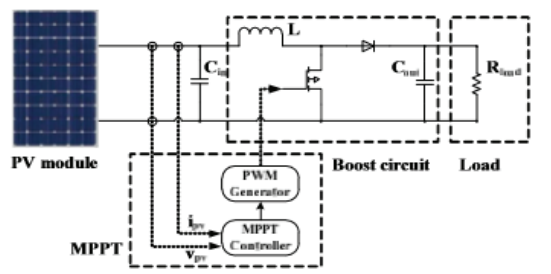

Figure 5. PV array with MPPT control

As the measure of daylight shifts, the heap trademark that is the characteristics of the load which gives the maximum energy transfer effectiveness changes, so the proficiency of the framework is upgraded when the heap trademark changes to keep the power exchange at most astounding productivity. This heap trademark is known as the greatest power point (MPP) and MPPT is the way toward discovering this point and keeping the heap trademark there. Electrical circuits can be intended to introduce self-assertive burdens to the photovoltaic cells and after that change over the voltage, current, or recurrence to suit different gadgets or frameworks, and MPPT takes care of the issue of picking the best load to be exhibited to the cells to get the most usable power out.

\section{Methodology of Peak Power Tracking}

MPP trackers are utilized to draw most extreme accessible power over the PV board for a given ecological condition. It can be Electro-Mechanical apparatuses or Electronics hardware. In this undertaking the MPP is followed by circuitbased re-enactment to guarantee the activity of the PV source at greatest power amid various natural conditions.

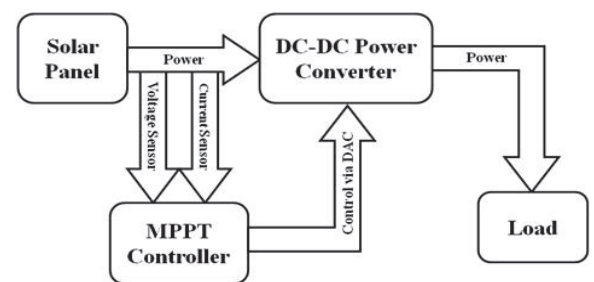

Figure 6.Proposed system for MPP Tracking with Boost Converter 
The point of MPPT is to control the real working voltage of PV board to the voltage at MPP, for this reason, MPPT modifies the yield intensity of inverter or DC converter as per the heap for the framework. If the PV yield voltage is higher than MPP voltage, at that point exchanged capacity to the heap or system is expanded, else, it is decreased.

\section{D.Modelling of a DC-DC Boost Converter}

Boost converter steps up the input voltage magnitude to a required output voltage magnitude without the use of a transformer. The main components of a boost converter are an inductor, a diode and a high frequency switch. These in a coordinated manner supply power to the load at a voltage greater than the input voltage magnitude. The control strategy lies in the manipulation of the duty cycle of the switch which causes the voltage change. The circuit diagram for a lift converter is shown in Figure 7. At the point when switch q is shut, the information source charges up the inductor while diode $\mathrm{D}$ is turned around one-sided to give disengagement between the information and the output of the converter. At the point when the switch is opened, vitality is put away in the inductor and the power supply is exchanged to the heap.

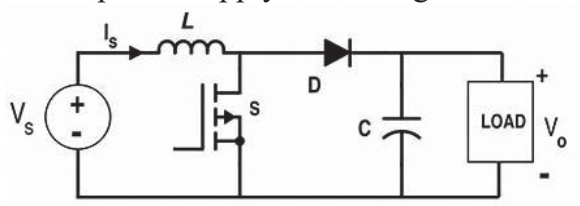

Figure 7. Circuit diagram for DC-DC Boost Converter

The output voltages are determined by the following equation

$$
\frac{V_{\text {out }}}{V_{\text {in }}}=\frac{1}{(1-D)}
$$

Where, $\mathrm{V}_{\text {out }}$ : Output voltage of the converter

$\mathrm{V}_{\text {in }}$ : Input voltage of the converter

D: Duty cycle of the switch 's'

The output current is given by the following equation assuming the converter as ideal.

$$
I_{\text {out }}=I_{\text {in }} \times(1-D)
$$

From the above equations it deduced that:

$$
\frac{V_{\text {out }}}{I_{\text {out }}}=\frac{V_{\text {in }}(1-D)}{I_{\text {in }}\left(1-D^{2}\right)}
$$

\section{E. Effects of Temperature}

Another imperative differentiator in sun powered PV execution, particularly in hot atmospheres, is the temperature coefficient of intensity. PV cell execution decays as cell temperature rises. For instance, in brilliant daylight, cell temperatures in Singapore can reach more than $70^{\circ} \mathrm{C}$, though $\mathrm{PV}$ modules are evaluated at a cell temperature of $25^{\circ} \mathrm{C}$. The misfortune in influence yield at $70^{\circ} \mathrm{C}$ is in this manner estimated as $(70-25) \times$ temperature coefficient. Most thin film innovations have a lower negative temperature coefficient contrasted with crystalline advancements. At the end of the day, they have a tendency to lose less of their appraised limit as temperature rises.

\section{MPPT TECHNIQUES}

\section{A. Perturb and Observe Method}

Perturb and Observe method results in top-level efficiency, provided that a proper predictive and adaptive hill climbing strategy is adopted The perturb and observe $(\mathrm{P \& O})$ method is the most popularly used algorithm that goes to the period of the direct MPPT techniques; it is characterized by the addition of a slight perturbation into the system, whose properties are used to determine the operating point near the MPP. In the P\&O method, the MPPT algorithm can be calculated by the PV output power and the power change obtained by sampling both the PV current and voltage. The tracker tracks by intermittently increasing or decreasing the solar voltage so that the MPP is tracked irrespective of the level of irradiance, changes in temperature, degradation, and aging, thus ensures high robustness and reliability.

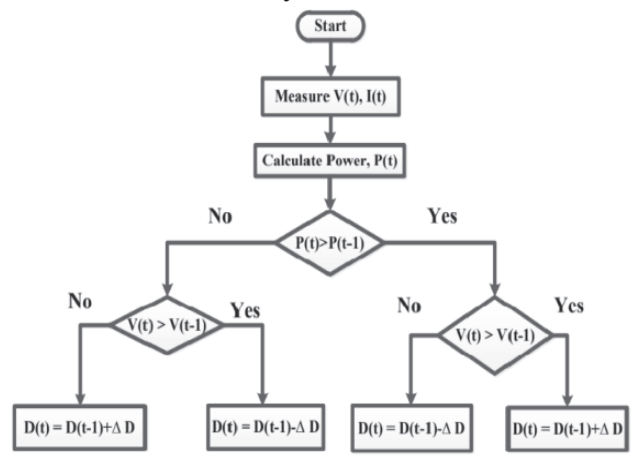

Figure 8. Flowchart for $\mathrm{P} \& \mathrm{O}$ Method

The P\&O method can be implemented by the PV operating point which is perturbed periodically by the change in PV source voltage terminals. Subsequently before and after the perturbation each perturbation, the control algorithm compares the values of the power fed by the PV source. After each perturbation, the PV power has increased and the operating point has been moved towards the MPP; therefore, the successive perturbation imposed to the voltage will have the same sign as the previous one. If after a voltage perturbation the power drawn from the PV array decreases, then the operating point has been moved away from the MPP. Therefore, the sign of the subsequent voltage perturbation is reversed. The switching converter is used to drive the perturbation of the operating voltage of the PV generator.The input voltage and input current obtained from the PV array system can be used to compute the instantaneous power of the given system. The maximum power point (MPP) is known and the duty ratio of the converter varies in accordance with the MPPT algorithm. The duty ratio is varied in such a way that the input power delivered to the converter will almost be equal to the power delivered to the load. Other methods derived by the P\&O approach are the incremental conductance(INC) and the conventional beta method. Such methods differ from the 
$\mathrm{P} \& \mathrm{O}$ approach either for the variable observed or for the type of perturbation. All these algorithms have the advantage of being independent of the knowledge of the PV generator characteristics.

\section{B. Incremental Conductance}

Incremental conductance is one of the important techniques in the MPPT system because of its higher steady-state accuracy and environmental adaptability it is widely implemented tracked control strategy. The main disadvantage of the 'Perturb and Observe Method' is to track the peak power of the solar panel under the fast-varying atmospheric condition. This disadvantage can be overcome by using Incremental Conductancemethod.

In incremental conductance method the array terminal voltage is always adjusted according to the MPP voltage.It is based on the incremental and instantaneous conductance of the PV module. The IC can determine that the MPPT has reached the MPP and stop perturbing the operating point. If this condition is not met, the direction in which the MPPT operating point must be perturbed can be calculated using the relationship between $\mathrm{dl} / \mathrm{dV}$ and $-\mathrm{I} / \mathrm{V}$.

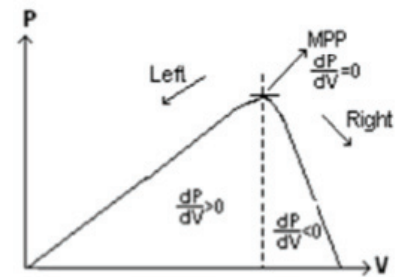

Figure 9. Incremental Conductance Method on a P-V Curve of Solar Module $d I / d V=-I V a t M P P$

$d I / d V>-I V l e$ ftof MPP $\ldots . .(2)$

$d I / d V<-I V r i g h$ tof $M P P$.....(3)

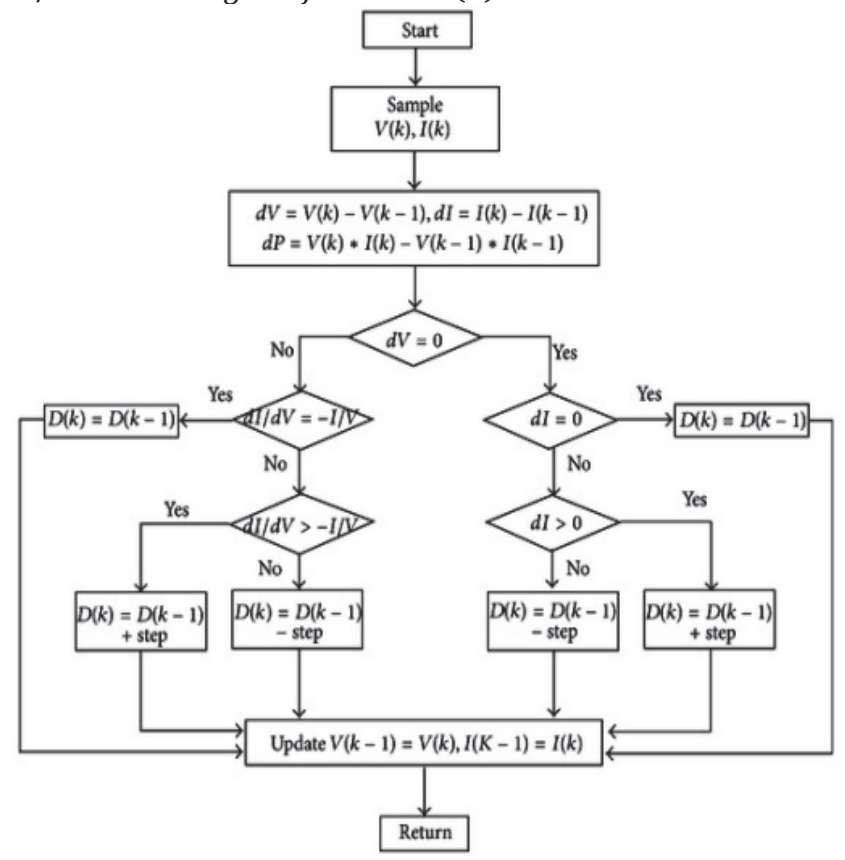

Figure 10. Flowchart for Incremental Conductance Method
This relationship is derived from the fact that $\mathrm{dI} / \mathrm{dV}$ is negative when the MPPT is to the right of the MPP and positive when it is to the left of the MPP. This algorithm has advantages over P\&O in that it can determine when the MPPT has reached the MPP, where P\&O oscillates around the MPP. Also, incremental conductance can track rapidly increasing and decreasing irradiance conditions with higher accuracy than $\mathrm{P}$ and $\mathrm{O}$.

\section{Conventional Beta Method}

The Conventional Beta method was first proposed by Jain and Agarwal the basic principle of conventional beta method is to track an intermediate variable $\beta_{\mathrm{a}}$ irrespective of the change in power. The intermediate variable $\beta_{\mathrm{a}}$ can be expressed by the following equation

$$
\beta_{\mathrm{a}}=\ln \left(\mathrm{I}_{\mathrm{pv}} / \mathrm{V}_{\mathrm{pv}}\right)-\mathrm{c} \times \mathrm{V}_{\mathrm{pv}}
$$

where $V_{p v}$ are the PV module output voltage and Ipv are the output current respectively. There is a diode constant ' $c$ ' which can be expressed as

$$
\mathrm{c}=\mathrm{q} /\left(\mathrm{N}_{\mathrm{s}} \mathrm{AKT}\right)
$$

where $\mathrm{q}$ is the electron charge $1.602 \times 10-19 \mathrm{C}$, A is the diode ideality factor, $\mathrm{K}$ is Boltzmann constant $1.38 \times 10-23 \mathrm{~J} / \mathrm{K}$, T (in Kelvin) is the temperature of the $\mathrm{p}-\mathrm{n}$ junction, and $\mathrm{N}_{\mathrm{s}}$ is cell number of the PV module.

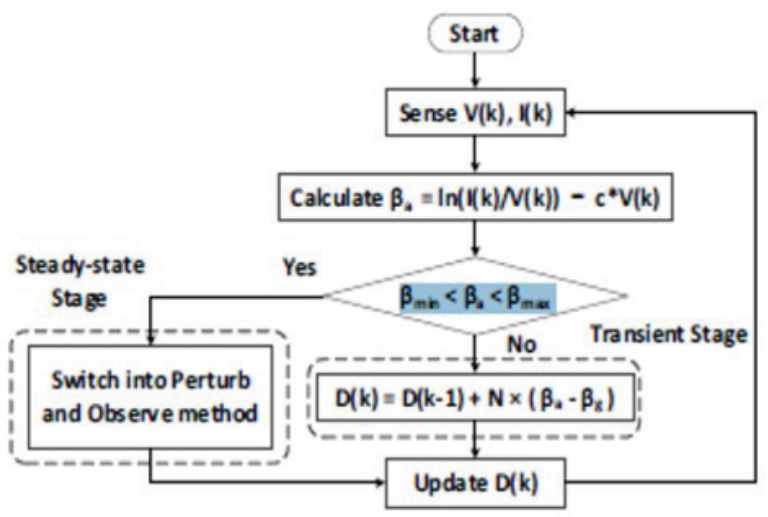

Figure 11. Flowchart of Conventional Beta Method

This method can be implemented in two stages: that is the transient stage and the steady-state stage. These two stages adapt to the variable step and fixed step respectively. In the implementation of the Beta method, the range of $\beta_{\text {min }}$ and $\beta_{\max }$ must be identified and, the algorithm calculates $\beta_{g}$ itself. Firstly, the voltage and current of a PV module output are measured, and then the actual values of $\beta_{\mathrm{a}}$ are calculatedcontinuously. If the value of $\beta_{\mathrm{a}}$ is within the limits of $\left(\beta_{\min }, \beta_{\max }\right)$, the Beta method switches into steady-state stage and the P\&O method will be implemented, otherwise the Beta method switches into the transient stage. In the transient stage, a guiding parameter $\beta_{\mathrm{g}}$ is adopted which is used in calculating the variable step size $\Delta \mathrm{D}$, which can be expressed as:

$$
\Delta \mathrm{D}=\mathrm{N} \times\left(\beta_{\mathrm{a}}-\beta_{\mathrm{g}}\right)
$$

where $\mathrm{N}$ is the scaling factor which indicates that the range of the parameter $\beta,\left(\beta_{\min }, \beta_{\max }\right)$ and parameter $\beta_{\mathrm{g}}$, needs to be 
identified. The range of the parameter $\beta$ depends on the environmental conditions of the PV module, such as the irradiance and temperature.

In the conventional Beta method, the converging speed for the rapid change in the environmental conditions depends onthe scaling factor. The performance of this method can be optimized by identifying the range of the parameter $\beta$ for various environmental conditions; furthermore, the scaling factor can be optimized through the parameter sweeping. Though, the optimal scaling factor subsequent from this process will be suitable for only limited operating conditions, additionally, the oscillations can still be observed in the steady state. Thus, there is a need for the potential of Beta method to further optimization for both steady-state and dynamic operations.

\section{Proposed Beta Method}

The Proposed MPPT method can be implemented by using two stages: 1) the Adaptive Scaling Factor Beta (ASF-Beta) which is used for transient state, and 2) the Zero Oscillations Perturb and Observe (ZOPO) which is used for the steady state. The flow chart of a proposed beta method is shown below. It consists of the Adaptive Scaling Factor Beta (ASFBeta) as shown in branches from (A) to (D), and the Zero Oscillations Perturb and Observe (ZOPO) as shown in branches $(\mathrm{E})$ to $(\mathrm{H})$.

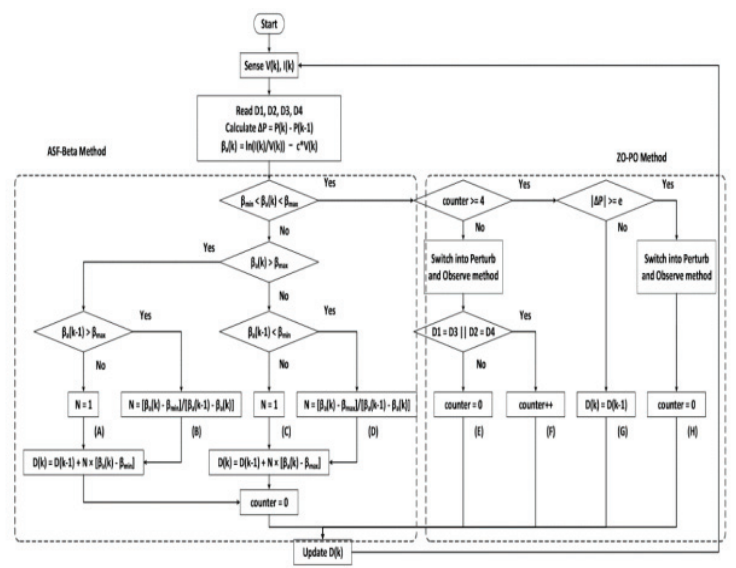

Figure 12. Flowchart of Proposed Beta Method

In the Conventional Beta method, the ASF-Beta method implements an adaptive scaling factor instead using the fixed scaling factor. The process to regulate the optimal scaling factor is removed and the guiding parameter $\beta_{\mathrm{g}}$ is eliminated in the practical implementation. Thus, the ASF-Beta becomes less dependent on the PV system. Also, the step size is automatically updated in the changes of parameter $\beta$ due to the environmental changes. Thus, the proposed method can attain a faster tracking convergence speed when compared to the conventional Beta method. Under the steady-state operation The Zero Oscillations Perturb and Observe (ZOPO) method identifies the middle point of the three-level perturbations. Therefore, the steady-state oscillations can be eliminated, which further helps in improving the tracking efficiency. By comparison with the $\mathrm{P} \& \mathrm{O}$ method and the variable step size incremental conductance (VSSINC) method, the main advantages of the proposed method are(1) By totally eradicating oscillations there will be high steady-state tracking efficiency; (2) by employing an adaptive scaling factor the dynamic efficiency of the system is improved; (3) the wrong step change instigated by the rapid change in the irradiance can be eliminated.

The PV system is modeled and simulated in MATLAB. In this model a PV panel of 10 cells per module having a maximum power of $59.85 \mathrm{~W}$ has been simulated with employment of both the ASF-BETA method and ZOPO method for a quite efficient MPP track. The duty cycle pulses have been fed to the DC-DC boost converter in accordance with the MPP value.

By comparing the results of all MPPT the proposed method shows the fastest method results among these methods to locate the MPP while the P\&O method is the slowest one in all cases. The VSSINC method is faster than the conventional Beta method when the irradiance is increased. Contrarily, the conventional Beta method is faster than the VSSINC method when the irradiance or resistance is decreased with these MPPT methods under the different irradiance levels. Due to a fixed step size, the power loss for the P\&O method and the conventional Beta method are almost the same, which are higher than other methods. The power loss for the VSSINC method is reduced compared with P\&O method and the conventional Beta method. Since the proposed method eliminates totally the oscillations, the power loss of this method is the smallest one under all irradiance levels.

\section{SIMULINK MOdEL AND RESUltS}

\section{A. Simulation results of $P \& O$}

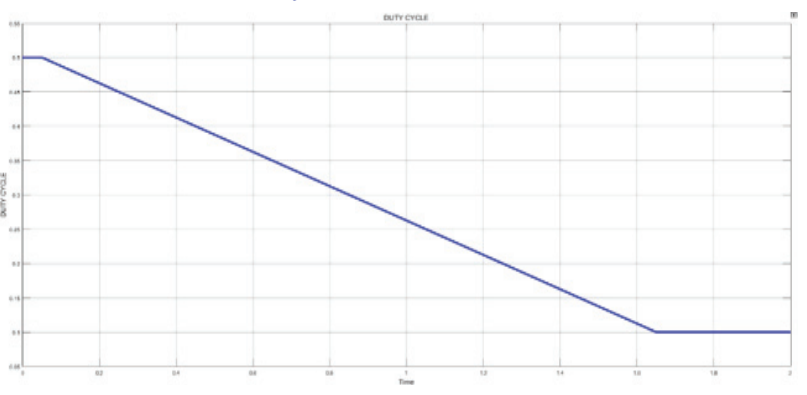

Figure 13. Simulation of $\mathrm{P} \& \mathrm{O}$ and its duty cycle (Secs)

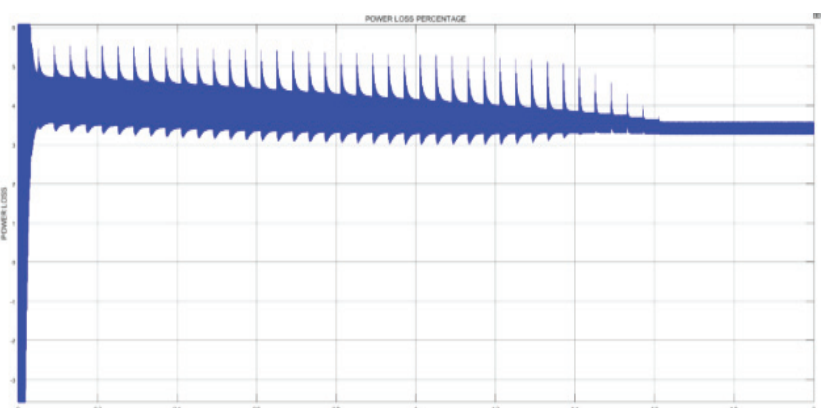

Figure 14. Simulation of MPPT P\&O and their Power Loss (Watts) 


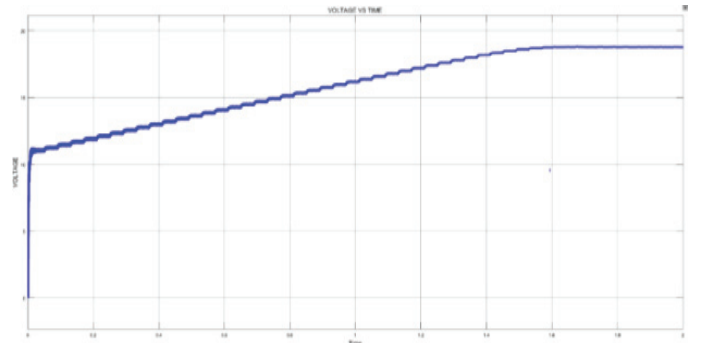

Figure 15.Simulation of MPPT P\&O and Voltage vs Time

The P\&O method simulation is done in MATLAB under various scenarios and has been analyzed including the variation of irradiance and different load variation conditions

At an irradiance of $500 \mathrm{w} / \mathrm{m}^{2}$ and a resistance of $5 \mathrm{ohms}$ the power loss is $4 \%$ and the tracking time taken by the system is $1.6 \mathrm{sec}$.At an irradiance of $600 \mathrm{w} / \mathrm{m}^{2}$ and a resistance of $5 \mathrm{ohms}$ the power loss is $4.5 \%$ and the tracking time taken by the system is $1.65 \mathrm{sec}$.At an irradiance of $800 \mathrm{w} / \mathrm{m}^{2}$ and a resistance of $5 \mathrm{ohms}$ the power loss is $6 \%$ and the tracking time taken by the system is $1.62 \mathrm{sec}$.

\section{B.Simulation results of INC}

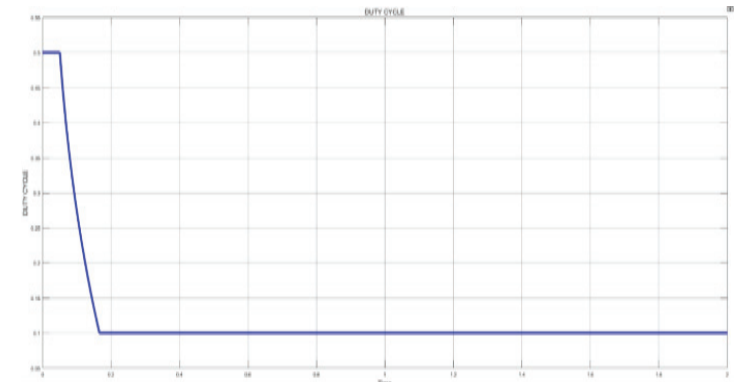

Figure 16. Simulation of $\mathrm{P} \& \mathrm{O}$ and its duty cycle

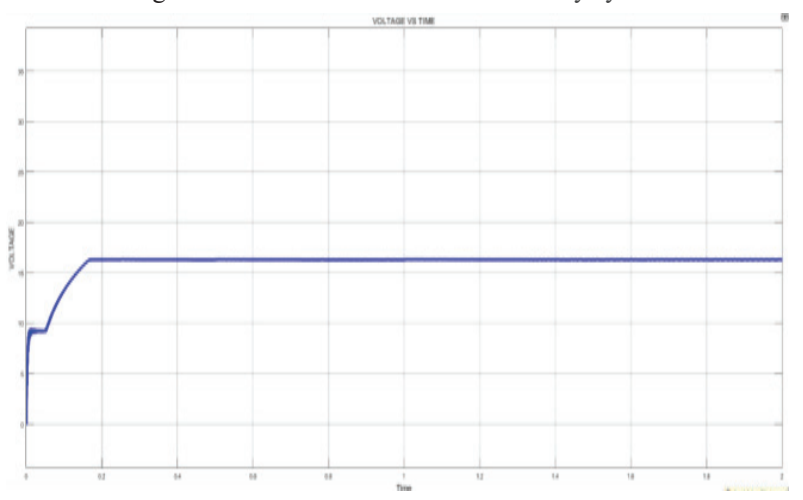

Figure 17. Simulation of MPPT INC and Voltage vs Time

The INC method simulation is done in MATLAB under Various scenarios and has been analyzed including the variation of irradiance and different load variation conditions

At an irradiance of $500 \mathrm{w} / \mathrm{m}^{2}$ and a resistance of $5 \mathrm{ohms}$ the power loss is $3.1 \%$ and the tracking time taken by the system is $1.17 \mathrm{sec}$.At an irradiance of $600 \mathrm{w} / \mathrm{m}^{2}$ and a resistance of 5 ohms the power loss is $3.5 \%$ and the tracking time taken by the system is $0.65 \mathrm{sec}$.At an irradiance temperature of
$800 \mathrm{w} / \mathrm{m}^{2}$ and a resistance of $5 \mathrm{ohms}$ the power loss is $3.5 \%$ and the tracking time taken by the system is $0.62 \mathrm{sec}$.

\section{C.Simulation results of Conventional Beta Method}

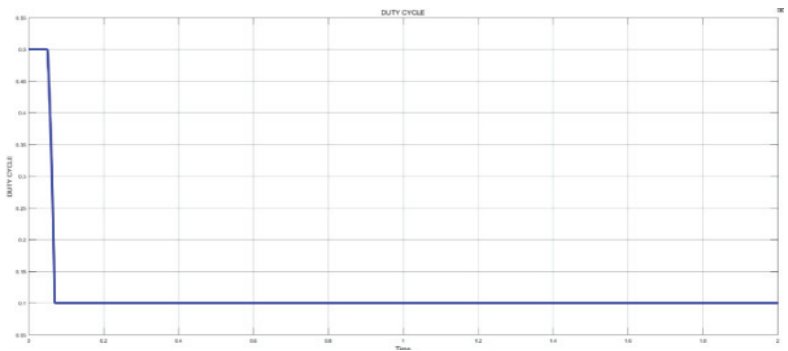

Figure 18. Simulation of Conventional Beta Method and its duty cycle

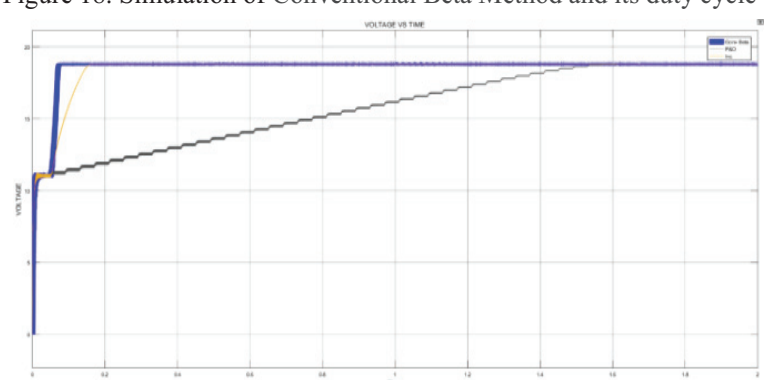

Figure 19. Simulation of Conventional Beta Method and Voltage vs Time

The conventional Beta method simulation is done in MATLAB under Various scenarios and has been analyzed including the variation of irradiance and different load variation conditions.At an irradiance of $500 \mathrm{w} / \mathrm{m}^{2}$ and a resistance of $5 \mathrm{ohms}$ the power loss is $3.6 \%$ and the tracking time taken by the system is $0.08 \mathrm{sec}$.At an irradiance of $600 \mathrm{w} / \mathrm{m}^{2}$ and a resistance of $5 \mathrm{ohms}$ the power loss is $3.6 \%$ and the tracking time taken by the system is $0.76 \mathrm{sec}$.At an irradiance of $800 \mathrm{w} / \mathrm{m}^{2}$ and a resistance of $5 \mathrm{ohms}$ the power loss is $3 \%$ and the tracking time taken by the system is 0.75 sec.

\section{D.Simulation results of Proposed Method}

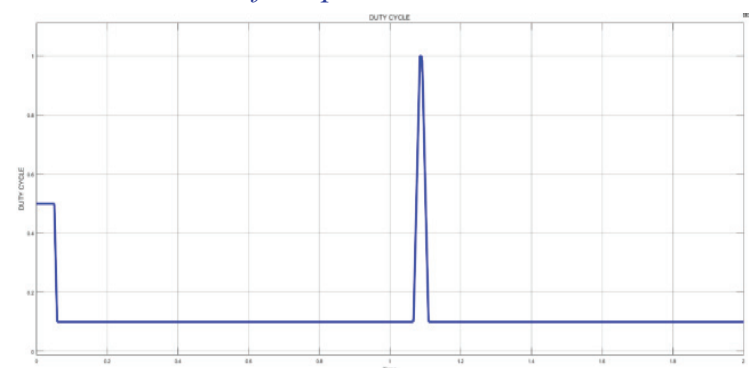

Figure 20. Simulation of Proposed Method and its duty cycle 


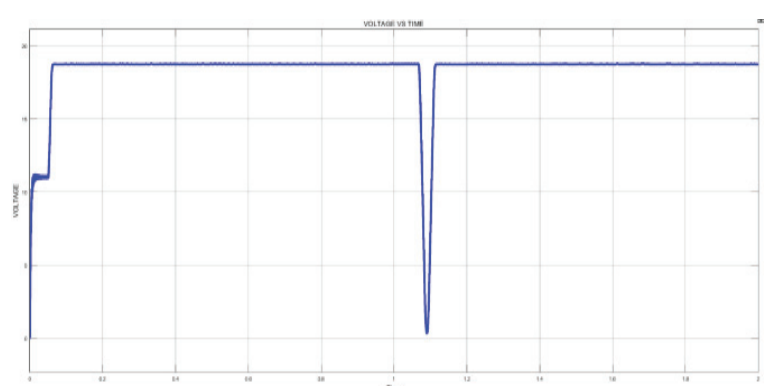

Figure 21. Simulation of Conventional Beta Method and Voltage vs Time

The Proposed Beta method simulations are done in MATLAB under Various scenarios and have been analyzed including the variation of irradiance and different load variation conditions. At an irradiance of $500 \mathrm{w} / \mathrm{m}^{2}$ and a resistance of $50 h m s$ the power loss is $3.2 \%$ and the tracking time taken by the system is $0.07 \mathrm{sec}$.At an irradiance of $600 \mathrm{w} / \mathrm{m}^{2}$ and a resistance of $5 \mathrm{ohms}$ the power loss is $3.3 \%$ and the tracking time taken by the system is $0.065 \mathrm{sec}$.At an irradiance of $800 \mathrm{w} / \mathrm{m}^{2}$ and a resistance of 5 ohms the power loss is $3.2 \%$ and the tracking time taken by the system is 0.065 sec.

\section{COMPARISON OF VARIOUS MPPT METHODS}

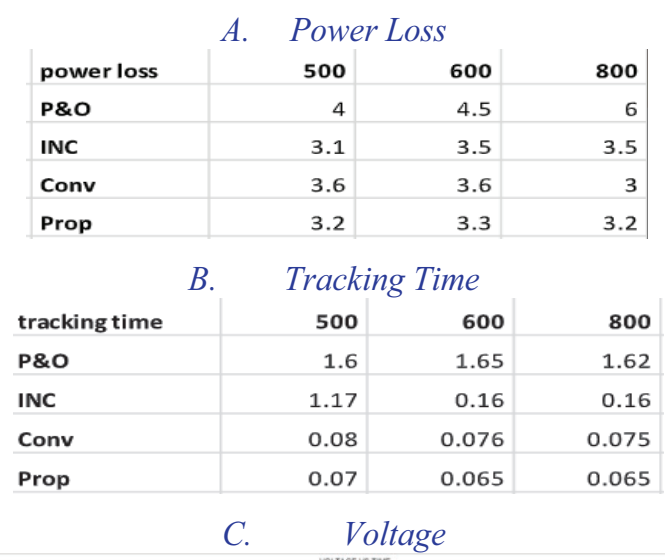

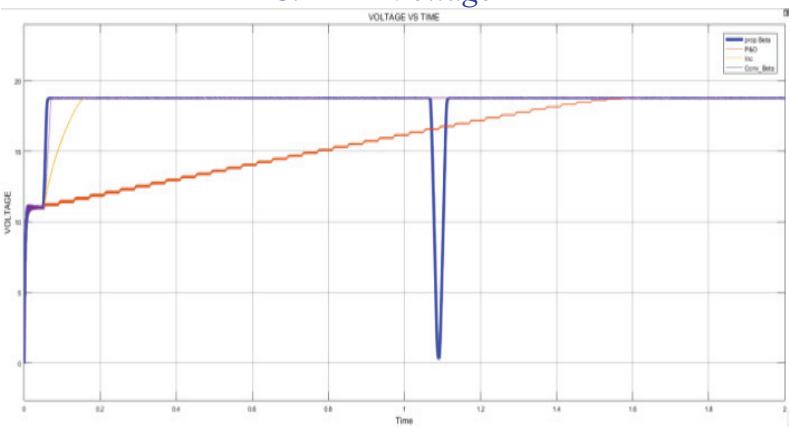

Figure 22. Simulation of MPPT Methods and their voltage (Volts)

From above all the comparison of the simulation results the proposed beta method shows higher performance by reducing the power loss and takes less tracking time.

\section{Conclusions}

The paper proposes a simple MPPT method that requires only measurements of Incremental conductance. MPPT algorithm is called Incremental conductance Method. However, by using this MPPT method we have increased the tracking efficiency. This method computes the maximum power and controls directly the extracted power from the PV. The proposed method offers different advantages which are: good tracking efficiency, response is high and well control for the extracted power.

The above MPPT method can be realized using two major stages: a) Adaptive Scaling Factor Beta (ASF-Beta) which helps in improving transient response of the system; and b) Perturb and Observe (ZOPO) which is used to eliminate steady-state errors in the system. The above methods are applied and tested under several scenarios and have been analyzed including the variation of irradiance and different load variation conditions. From the above simulation results, the higher performance of the proposed algorithm can be validated over all the other MPPT methods. From the above simulation results, it can also be demonstrated that the overall tracking speed of the proposed method is much faster when compared to other MPPT methods like P\&O method, VSSINC method and conventional Beta methods. Through the transient stage, the power loss in the system can be reduced in comparison with the P\&O method, VSSINC method, and conventional Beta methods due to the Zero Oscillations Perturbation and Observe method helps in reducing the steady state oscillations.

\section{REFERENCES}

[1] N. Femia, G. Petrone, G. Spagnuolo, and M. Vitelli, "Optimization of perturb and observe maximum power point tracking method," IEEE Trans. Power Electron., vol. 20, no. 4, pp. 963-973, Jul. 2005.

[2] A. Safari and S. Mekhilef, "Simulation and hardware implementation of incremental conductance MPPT with direct control method using cuk converter," IEEE Trans. Ind. Electron, vol. 58, no. 4, pp. 1154-1161, Apr. 2011.

[3] P. Lezana and G. Ortiz, "Extended operation of cascade multicell converters under fault condition," IEEE Trans. Ind. Electron., vol. 56, no. 7, pp. 2697-2703, Jul.2009.

[4] T. K. Soon and S. Mekhilef, "Modified incremental conductance MPPT algorithm to mitigate inaccurate responses under fastchanging solar irradiation level," Solar Energy, vol. 101, no. 0, pp. $333-342,2014$.

[5] Q. Mei, M. Shan, L. Liu, and J. Guerrero, "A novel improved variable step-size incremental-resistance MPPT method for PV systems," IEEE Trans. Ind. Electron, vol. 58, no. 6, pp. 2427 2434, Jun. 2011

[6] H. Yohan, S. N. Pham, Y. Taegeun, C. Kookbyung, B. KwangHyun, and K. Yong Sin, "Efficient maximum power point tracking for a distributed PV system under rapidly changing environmental conditions," IEEE Trans. Power Electron., vol. 30, no. 8, pp. 4209-4218, Aug. 2015

[7] D. Sera, L. Mathe, T. Kerekes, S. V. Spataru, and R. Teodorescu, "On the perturb-and-observe and incremental 
conductance MPPT methods for PV Systems," IEEE J. Photovoltaics, vol. 3, no. 3, pp. 1070-1078, Jul. 2013.

[8] L. Xu, R. Cheng, J. Yang, "A New MPPT Technique for fast and efficient tracking under fast varying solar irradiation and load resistance," International Journal of Photo Energy, Vol.2020, pp. 1-18.

[9] X. Li, H. Wen, G. Chu, H. Hu, L. Jiang, "A Novel powerincrement based GMPPT algorithm for PV arrays under partial shading conditions," Journal of Solar energy, vol.169, 2018, pp. 353-361.

[10]. X. Li, H. Wen, L. Jiang, W. Xiao, Y. Du, Ch. Zhao, "An improved MPPT method for PV system with fast converging speed and zero oscillation," IEEE Transactions on Industry, Vol 52, issue 6, 2016, pp.5050-5064. 